\title{
perifèria
}

Número 16, junio 2012

revistes.uab.cat/periferia - www.periferia.name

\section{La gestión de los comunes en México: hacia un modelo de análisis de los ejidos}

\author{
Esther Fernández Moya \\ Doctoranda en Estudios Postcoloniales y Ciudadanía Global \\ Universidad de Coimbra- Centro de Estudios Sociales ${ }^{1}$
}

\section{Resumen}

En este artículo se presentan algunos resultados y cuestionamientos que surgieron a través de la investigación "Las instituciones locales de acción colectiva en la gestión de los comunes en México: el Ejido tras las reformas agrarias de 1992" realizado en el marco del Máster en Investigación etnográfica, teoría antropológica y relaciones interculturales de la Universidad Autónoma de Barcelona (UAB) 20102011. Como objetivo principal de esta investigación se analizaron las consecuencias de las reformas agrarias emprendidas desde 1992 en las instituciones locales de acción colectiva de los ejidos. El ejido es la figura jurídica más representativa de la propiedad colectiva en México. Por otra parte, nos centramos en el programa PROCEDE (Programa de Certificación de Derechos Ejidales y Titulación de Solares Urbanos) como la principal herramienta de la Ley Agraria de 1992 y la reforma del artículo 27 Constitucional. Asimismo, en este artículo se aporta la propuesta metodológica para el análisis de casos (ejidos) en el proceso de estas reformas legislativas.

Palabras clave: Ejido, comunes, instituciones locales de acción colectiva, PROCEDE y propiedad social. 


\title{
perifèria
}

Número 16, junio 2012

revistes.uab.cat/periferia - www.periferia.name

\begin{abstract}
This article presents some results and questions that emerged through the research "Local institutions for collective action in managing common in Mexico: the Ejido after the land reform of 1992" made for the Master in Ethnographic Research, Anthropological Theory and Intercultural Relations at the Autonomous University of Barcelona(UAB) 2010 - 2011. As the main goal of this research I analyzed the impact of land reforms undertaken since 1992 in local institutions for collective action of the ejidos. The ejido is the main legal form of common property in Mexico. Moreover, we focus on the PROCEDE program (Program of Certification of Ejido Rights and Titling of Urban Patios) as the main tool of the Agrarian Law of 1992 and the reform of Article 27 of the Constitution. Also, this article provides a methodological proposal for analyzing ejidos case studies in the context of these legislative reforms.
\end{abstract}

Key words: Ejido, commons, local institutions for collective action, PROCEDE, and social property.

\section{Introducción}

El objetivo principal de la investigación fue analizar las consecuencias de la Ley Agraria de 1992 de México en las instituciones locales de acción colectiva encargadas de gestionar los comunes. Nuestra hipótesis de partida fue que las reformas agrarias emprendidas desde 1992 habían provocado por una parte, el debilitamiento de las instituciones locales de acción colectiva de los ejidos, y por otra parte, habían creado tanto resistencias colectivas como estrategias de supervivencia "alternativas" al proyecto federal de privatización y apertura del "campo" al libre mercado.

Para analizar esta hipótesis nos centramos en los discursos ocultos (Scott, 2004) y en las reinterpretaciones que tanto desde las autoridades estatales y municipales como desde los propios ejidos, elaboraban en base a los diferentes contextos 


\section{perifèria}

Número 16, junio 2012

\section{revistes.uab.cat/periferia - www.periferia.name}

locales. Para ello fueron seleccionados seis estudios de caso, de los cuales cinco estudios fueron analizados a partir de fuentes secundarias, y un sexto estudio de caso elaborado a través de una estancia de campo en la Unión Veinte de Junio (Campeche).

A continuación expondré brevemente las principales referencias teóricas e históricas que sustentaron esta investigación. Por una parte, nos basamos en el axioma biocultural como la conservación simbiótica en la cual la diversidad biológica y cultural son mutuamente dependientes y geográficamente superpuestas (Nietschmann 1992). Esta vinculación entre la diversidad cultural y la diversidad biológica ha sido estudiada por diferentes autores que vinculan ciertos endemismos biológicos con conocimientos ecológicos locales (Boege 2004; Maffi 2001).

Por otra parte, analizamos el concepto de comunes en relación con las formas de apropiación de la naturaleza. En este sentido, dentro de los comunes encontramos recursos con una ubicación fija, como los bosques, o con una ubicación móvil como los recursos pesqueros, e incluso otros casos, como los océanos, que se presentan como indivisibles. En este caso además hemos de distinguir entre comunes globales como la atmósfera y comunes locales como pueden ser los prados utilizados para el pastoreo. Cualquiera de estos tipos de comunes también pueden dividirse en aquellos considerados recursos renovables como los bosques, o recursos no renovables como puede ser considerada la minería (Merino 2004). Esta investigación tiene como objeto central de estudio, la propiedad colectiva en el México rural de los siglos XX y XXI, como una tipología de común local, de ubicación fija, divisible, y que concierne recursos renovables, prestando especial atención a los que están configurados bajo la figura jurídica del ejido.

La propiedad colectiva de recursos naturales la podemos encontrar en todas las regiones de la tierra, y aunque han disminuido considerablemente, actualmente aún persisten. De esta manera, aunque muchos de los comunes han pasado de propiedad colectiva a otro tipo de propiedad (privada o estatal), su gran persistencia aún la hemos de asociar con su efectividad para con la gestión de los recursos (Chamoux y Contreras 1996; Berkes 2002; Merino 2006). Así pues, tal y 


\section{perifèria}

Número 16, junio 2012

\section{revistes.uab.cat/periferia - www.periferia.name}

como apunta Pascual (1996) el mantenimiento de la propiedad colectiva va más allá del rendimiento económico que proporciona, sino que, debe ser pensada desde la mayor efectividad en la gestión social y política en relación con otras formas de propiedad.

La gestión local de los comunes, se caracteriza por una intervención mínima o nula de las administraciones de los gobiernos estatales, siendo las comunidades locales las principales protagonistas en todo el proceso de manejo y gestión de los recursos naturales de su entorno. Además la gestión local de los comunes acostumbra a tener un reconocimiento, o al menos algún tipo de tratamiento jurídico, por parte de la administración del gobierno estatal en los derechos de propiedad y gestión comunitaria de los recursos (Merino 2006). En este sentido, estas experiencias de gestión local de los comunes tienen cierto grado de autonomía reconocido formal y/o informalmente por las instancias gubernamentales a través del pluralismo jurídico. Es decir, tienen la particularidad de romper con el binomio "un Estado un derecho", creando la posibilidad de visibilizar fenómenos jurídicos complejos que se dan en territorios y desde prácticas que difieren de la validez jurídica del derecho estatal (Mercado y Cohen 2010; Sousa Santos 2005; Ostrom 2005).

En el contexto geográfico que nos ocupa, México ha sido reconocido internacionalmente por el éxito en el manejo comunitario de recursos naturales, especialmente en recursos forestales y en los estados del Sudeste mexicano (Bray y Merino 2004). Estas experiencias de manejo comunitario de recursos en tenencia comunal o ejidal, se caracterizan también por ciertas formas de organización colectivas sustentadas por normas y costumbres anteriores a la Reforma Agraria de 1917 y que han sido reelaboradas a lo largo de la historia (Zendejas y Vries 1998). Estas normas y costumbres que conforman los derechos y obligaciones de la comunidad o el ejido, se estructuran a través de instituciones locales de acción colectiva. En este sentido, en esta investigación se revisaron las aportaciones de Ostrom desde su relevante obra El Gobierno de los Bienes Comunes (1990) hasta sus investigaciones actuales, que en su conjunto le han merecido el premio Nobel en 2009. Además de las aportaciones de otros importantes autores que se han centrado en el estudio de las instituciones locales de acción colectiva (Agrawal 


\section{perifèria}

Número 16, junio 2012

\section{revistes.uab.cat/periferia - www.periferia.name}

2001; Merino 2004; Rentería 2010; Achenson 1991). Entendemos por instituciones locales de acción colectiva el conjunto de reglas formales e informales que estructuran la interacción social y que se construyen a través de acuerdos puestos en práctica en contextos específicos y construidos, gestionados, sancionados y modificados por los usuarios de los recursos de uso común (Ostrom y Ahn 2003; Ostrom y Hess 2007).

Desde el contexto mexicano, estas reformas tenían como objetivo implícito parcelar y privatizar las tierras comunales y ejidales, propiciando así la entrada de capital privado en el campo, lo cual facilitaría además la entrada de México en el $\operatorname{TLCAN}^{2}$ (Tratado de Libre Comercio de Norteamérica) (Zendejas y Vries 1998; Varo 2002). Para legitimar estas reformas, el discurso oficial versó sobre la seguridad en la tenencia que produce la titularidad otorgada por la parcelación de las tierras como pequeños propietarios, versus la tenencia en régimen de "propiedad social". Pero tal y como demuestran otras investigaciones (Maldonado 2010; Rentería 2011; Concheiro et al. 2001), la inseguridad en la tenencia de la tierra en régimen de "propiedad social" es una falsa premisa, que se utilizó para promover una reconfiguración de los derechos y obligaciones sociales que permitiera mercantilizar la propiedad a través de la liberalización de los derechos.

La firma de este tratado en México se realiza en 1994 dos años después de la Ley Agraria y la reforma del art. 27 Constitucional. Aunque las negociaciones de firma de este tratado se iniciaron antes de la Ley Agraria de 1992 siendo esta circunstancia uno de los antecedentes que dieron cabida a las reformas iniciadas en 1992. 


\section{perifèria}

Número 16, junio 2012

\section{revistes.uab.cat/periferia - www.periferia.name}

\section{De la tragedia de los comunes al buen gobierno de los comunes}

La expresión "tragedia de los bienes comunes" se popularizó con la publicación de un artículo en la revista Science en 1968 del biólogo G. Hardin con el título "The Tragedy of the Commons". Esta publicación apareció en un contexto donde existía un auge del movimiento ecologista, hippie y neo-comunitarista, especialmente en Estados Unidos. Su tesis, que fue publicada en gran medida con el objetivo de contrarrestar y poner en duda estas tendencias contraculturales y su transgresión al ámbito científico, supuso un duro golpe a ese tipo de posiciones ecologistas.

La tesis de Hardin sirvió a diversos académicos y políticos desde entonces, para criticar la gestión comunitaria de recursos naturales y favorecer la gestión privada o, a lo sumo, la estatal. La tragedia de los comunes se sustenta por un análisis del comportamiento del individuo aislado, tal y como se plantea desde el dilema del prisionero, de manera que aparece como inevitable el comportamiento oportunista (free rider). Este análisis reduccionista se basa en un individuo ajeno al resto de la comunidad o sociedad. Además, la propuesta de Hardin, igual que otros análisis sobre los comunes, produce confusión al utilizar el concepto de propiedad colectiva como sinónimo de acceso abierto. Tal vez el error más fundamental del famoso texto de Hardin, ya que el acceso abierto es una tipología de gestión que puede ser o no de propiedad colectiva.

Por otra parte, Elinor Ostrom fue premiada con el Nobel en Economía en 2009 por su obra El Gobierno de los bienes comunes. La evolución de las instituciones de acción colectiva (1990). Esta autora es una de las principales estudiosas de los recursos de uso común (RUCs) ${ }^{3}$ y defensora de la potencialidad de las instituciones de acción colectiva. Los recursos de uso común hacen referencia a un sistema de recursos naturales, caracterizados por la dificultad de excluir a destinatarios potenciales de los beneficios de su uso (Ostrom 1990).

Lo que se cuestiona Ostrom en esta obra es cómo un grupo de personas que se encuentran en situación de interdependencia puede organizarse para obtener 


\section{perifèria}

Número 16, junio 2012

\section{revistes.uab.cat/periferia - www.periferia.name}

beneficios conjuntos ininterrumpidos, evitando o minimizando la actitud del oportunista (free rider). Para resolver esta cuestión, Ostrom apuesta por el desarrollo del concepto de institución local, el cual se construye a través de acuerdos puestos en práctica en contextos específicos y construidos, gestionados, sancionados y modificados por los usuarios de los recursos de uso común (Ostrom y Ahn 2003).

De esta manera, las instituciones locales de acción colectiva deberán enfrentarse a los problemas de apropiación (distribución de las unidades de un recurso en el tiempo y el espacio), de provisión (las inversiones necesarias para el mantenimiento de los sistemas y los recursos naturales), de compromiso (credibilidad en el cumplimiento de las normas establecidas colectivamente) y de supervisión (creación de sistemas de seguimiento internos) (Ostrom 1990; Berkes 2002; Merino 2006). 


\section{perifèria}

Número 16, junio 2012

\section{revistes.uab.cat/periferia - www.periferia.name}

\section{Propiedad social y Reforma Agraria en México}

Para contextualizar históricamente la propiedad social en México hemos de hacer referencia a la Reforma Agraria de 1917. Esta reforma agraria postrevolucionaria, conllevó básicamente dos estrategias diferenciadas según sus propios actores. Por una parte, tenemos a los campesinos y jornaleros sin posesiones terrenales que demandaban la redistribución de las tierras desde el Estado. Y por otra parte, a los comuneros indígenas que reivindicaban el reconocimiento de sus comunidades y la titularidad colectiva de las tierras que les arrebataron durante el período colonial (Dietz 2005; Rentería 2011; Zendejas y Vries 1998; Varo 2002).

Por ello, a partir de entonces, encontramos dos tipologías de propiedad social:

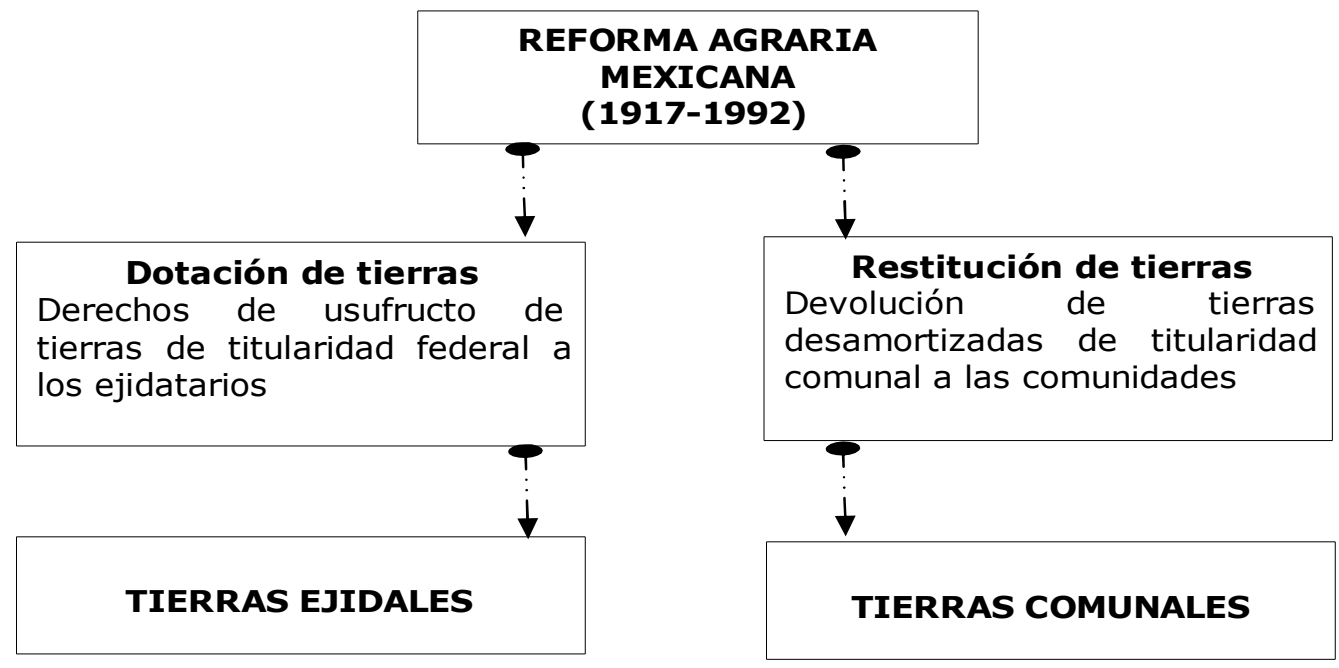

+ Tierras de propiedad privada

Figura 1. Reforma Agraria Mexicana (1917-1992). Fuente: Dietz 2005.

Tal y como observamos en el esquema, durante la Reforma Agraria postrevolucionaria (1917) se llevó a cabo un reparto de las tierras de "propiedad 


\section{perifèria}

Número 16, junio 2012

\section{revistes.uab.cat/periferia - www.periferia.name}

social" conforme a dos estrategias: la dotación y la restitución.

La dotación fue el mecanismo a través del cual, los campesinos que carecieran de tierra o se considerase que no tuvieran suficiente, podían solicitarla a través de la constitución de un ejido. Este mecanismo resultó ser un proceso burocrático complejo aunque fue la estrategia mayormente promovida desde la reforma (Varo 2002). A través de este mecanismo surge la figura jurídica del ejido. La restitución fue la estrategia a través de la cual las comunidades agrarias que habían perdido ilegítimamente sus tierras durante las políticas liberales del siglo XIX como la Ley Lerdo de Desamortización de 1856 y el Porfiriato, podían reclamarlas a través de títulos u otros certificados que cercioraran su pérdida. Esta estrategia fue todavía más compleja y no hubo un interés especial en la restitución de las tierras a lo largo de la reforma. (De Ita 2003; Rentería 2011; Rivera 2007).

Desde la Reforma Agraria de 1917 se promovió principalmente la creación de la figura del ejido. Los ejidatarios poseen la tierra colectivamente, mediante un acceso dual de derechos: por una parte tienen parcelas individuales en usufructo; y por otra parte, las tierras comunales de acceso y uso regulado. Las limitaciones legislativas del ejido prohíben la venta o renta de las tierras y se establece una herencia a una única persona, pudiendo perder la dotación si reside fuera de la región por un período superior dos años o por cultivar estupefacientes (Braña 2005, Mackinlay 1991). Los derechos sobre estos bienes agrarios, ya sea por dotación o restitución son bienes inembargables, inalienables, imprescriptibles e intransmisibles (Martín Trujillo 2009).

La reforma agraria durante su implementación (1917-1992) no logró llevar a cabo los postulados democráticos de repartición de las tierras, promoviendo a la práctica el desarrollo de empresarios agrícolas a través de la dotación de las mejores tierras; y por otra parte, se creó un sistema clientelar-corporativo en torno a las tierras menos productivas con el objetivo de controlar al campesinado más pobre (Zendejas y Vries 1998; Dietz 2005). Aunque esta reforma agraria salvaguardó de alguna manera la tenencia de "propiedad social" (comunal o ejidal), no fue lo suficientemente eficiente como para llegar a todas las comunidades rurales de 


\section{perifèria}

Número 16, junio 2012

\section{revistes.uab.cat/periferia - www.periferia.name}

México, que reclamaban la recuperación de sus tierras o la formación de nuevos ejidos (Rentería 2011).

A principios de 1990, las organizaciones empresariales empezaron a reclamar la revisión de la Ley Federal de la Reforma Agraria para poder regular las prácticas que ya se estaban llevando a cabo con ejidatarios y comuneros de manera ilegal. Las propuestas iban encaminadas a la apertura y liberalización del régimen ejidal y comunal, a través de la legalización del arrendamiento y la venta de las tierras, así como la ampliación de las modalidades de asociación de los inversionistas externos con ejidatarios y comuneros (Varo 2002). Estas reclamaciones fueron aprovechadas para promover una nueva Ley Agraria en 1992.

Los objetivos de la Ley Agraria de 1992 con la subyacente reforma del art. 27 Constitucional los podemos resumir en (De Ita 2003; Ruiz Massieu 1994; Robles 2008; Concheiro et al. 2001):

1. Finalizar con la obligación del Estado en la repartición de tierras. El fin de la repartición de las tierras promovidas desde la reforma agraria de 1917, finaliza con la Ley Agraria de 1992 desde la cual se señala la imposibilidad de continuar con la repartición por la inexistencia de tierras a repartir.

2. Dar certidumbre al campo mediante la certificación y parcelación de las tierras. Se apuesta por la certificación y obtención de títulos de propiedad, a través de la parcelación de las tierras ejidales o comunales sustentado a través del programa PROCEDE (Programa de Certificación de Derechos Ejidales y Titulación de Solares Urbano) que se pone en marcha en 1993.

3. Los ejidatarios o comuneros que han obtenido el certificado de parcelación de sus tierras pueden venderlas o rentarlas a través de la aprobación en la asamblea general.

4. Las tierras comunes usadas por los ejidatarios de manera colectiva, como las zonas de pastoreo o forestales, también están sujetas a la 


\section{perifèria}

Número 16, junio 2012

\section{revistes.uab.cat/periferia - www.periferia.name}

posibilidad de privatización.

5. Ya no es obligatorio que el ejidatario, como propietario de la tierra, trabaje sus propias parcelas.

6. Promover la creación de grandes Unidades Productivas que promuevan la capitalización del campo y llegar a escalas de producción competitivas.

7. Desaparición de los precios de garantía para productos agrícolas y eliminación de los subsidios. Para compensar esta situación se establece el programa Procampo con el objetivo de compensar a los productores de grano básico por la pérdida en la rentabilidad de sus cultivos, debido a la supresión de los precios de garantía y a la apertura comercial al mercado.

8. Antes de la reforma del art. 27 Constitucional de 1992, la herencia se daba a un único individuo de la comunidad, normalmente a la mujer o a sus hijos. Con la nueva reforma, el derecho individual con relación a la compra-venta de tierra ejidal puede darse libremente al interior de la comunidad, siempre y cuando el comprador no acumule más del cinco por ciento de la tierra ejidal bajo su propiedad. Pero esta libertad individual, ha afectado negativamente al núcleo familiar, ya que la parcela deja de ser en muchos casos un usufructo familiar. Siendo además las mujeres las que sufren mayor exclusión como beneficiarias de este nuevo reparto agrario. Por otra parte, además la reforma impone la asimilación al aparato jurídico estatal, a través de la obligación de realizar un largo y costoso proceso burocrático, para llevar a cabo la dotación a través de la herencia.

Sin lugar a duda, estas reformas vinieron suscitadas por el interés de México en firmar el Tratado de Libre Comercio de América del Norte (TLCAN), ya que la preocupación de la inseguridad en la tenencia de la tierra suponía el mayor obstáculo para las inversiones extranjeras en el campo mexicano (Hernández 2001, 


\section{perifèria}

Número 16, junio 2012

\section{revistes.uab.cat/periferia - www.periferia.name}

Téllez 1994). En 1994 México firmó el TLCAN. Este tratado produjo la caída de los productores forestales mexicanos, ya que resultaban más baratos los productos forestales de importación. Además, las repercusiones del TLCAN fueron desde la privatización de las tierras forestales a la creación de nuevas formas de manejo colectivo, ésta última como estrategia adaptativa al nuevo contexto impuesto por el TLCAN (Falconí et al. 2004).

La reforma del artículo 27 Constitucional fue implementada a partir de 1993 con el programa PROCEDE (Programa de Certificación de Derechos Ejidales y Titulación de Solares Urbanos), como instrumento generador de seguridad en la tenencia de la tierra, a través de la creación de certificados de propiedad individual para ejidatarios y comuneros. Entre sus funciones estaban: delimitar las colindancias de los ejidos, medir y certificar los derechos de las parcelas y regularizar los derechos agrarios. El gobierno salinista tenía previsto que finalizara la certificación de los derechos a través de este programa en 1994; sin embargo, no contaron con el rechazo inicial de diversos ejidos y comunidades a este programa como una forma de resistencia a la reforma del art. 27 Constitucional (De Ita 2003).

Casi veinte años después de la implementación de programa PROCEDE, diversos estudios de caso han sustentado que las resistencias hacia este programa se han realizado principalmente desde estados con una alta densidad de población indígena y con alta proporción de tierras comunales, como es el caso de Oaxaca o Guerrero (De Ita 2003; Léonard 2003).

A través del análisis de las investigaciones (De Ita 2003; Robles 2008; Vargas et al. 2008; Mattiace 2002; Concheiro et al. 2001; Léonard y Velázquez 2007; Hernández 2001) que se han centrado en las consecuencias de esta reforma legislativa, podemos enunciar las siguientes consecuencias:

1. Generalización de la compra-venta a personas ajenas del ejido. Desde el fin del reparto de tierras a través de la Ley Agraria de 1992 la única forma de acceder a la tierra es o a través de la herencia, o de la venta-renta de las mismas.

2. Desarticulación de la organización comunitaria a causa del aumento del 


\section{perifèria}

Número 16, junio 2012

revistes.uab.cat/periferia - www.periferia.name

protagonismo de agentes externos como nuevos propietarios y la mayor presencia de sujetos agrarios como los avecindados o posesionarios.

3. Procesos migratorios elevados campo-ciudad: muchos campesinos migran hacia las urbes como nueva fuerza de trabajo descomunalizada, a consecuencia de la renta y venta de las tierras parceladas.

4. Aumento del suelo urbano: las tierras vendidas a personas ajenas a la comunidad se convierten, en gran parte, en suelo urbanizable.

5. Aunque continúa siendo mayoritaria la "propiedad social", ejidal o comunal, ha habido un aumento de la parcelación de las tierras y en las posesiones individuales. Lo cual no indica necesariamente un minifundismo, sino como veremos más adelante, puede generar nuevas formas de latifundismo. 


\section{perifèria}

Número 16, junio 2012

\section{revistes.uab.cat/periferia - www.periferia.name}

\section{Modelo de análisis de los factores internos y externos que afectan al ejido desde las reformas de 1992}

En este apartado presento el modelo de análisis elaborado a partir de la investigación presentada en la tesina, con algunas modificaciones que han surgido en el posterior proceso de investigación. El objetivo de esta propuesta es crear un marco de análisis multidimensional de los factores internos y externos, que influencian el contexto local del ejido ante las reformas agrarias llevadas a cabo desde 1992.

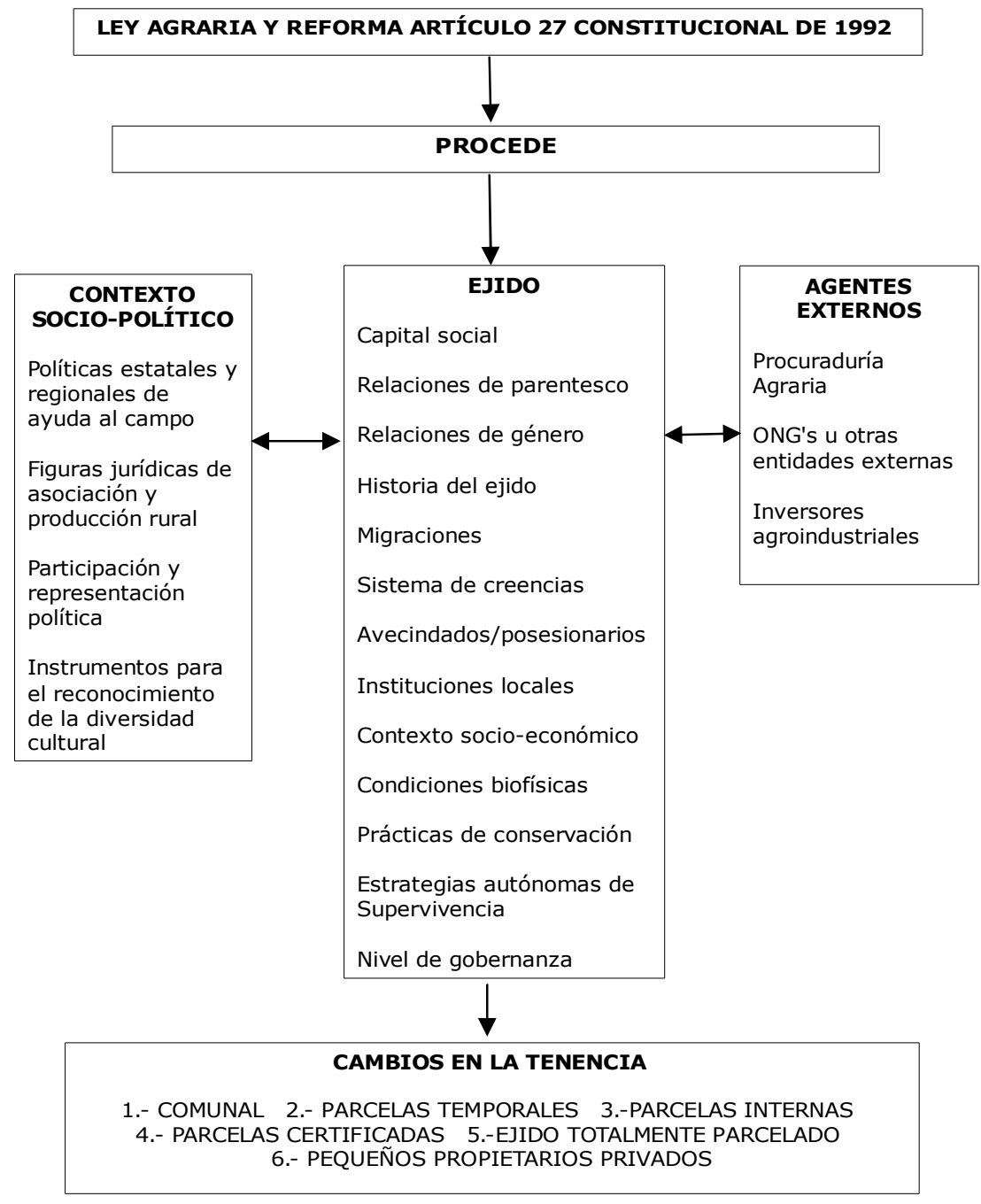

Figura 2. Modelo de análisis para los estudios de caso. 


\section{perifèria}

Número 16, junio 2012

\section{revistes.uab.cat/periferia - www.periferia.name}

Con este esquema pretendemos mostrar la complejidad de la(s) realidad(es) local(es) que afectan y son afectadas a partir del proceso de cambio legislativo, iniciado en 1992 y dirigido a la regulación de la tenencia de la tierra en régimen de propiedad social en México. En el centro del esquema ubicamos al ejido como figura jurídica que representa una forma de propiedad social, y por lo tanto colectiva, y en la que hemos centrado nuestra investigación. El resto de variables que hemos introducido alrededor de la figura del ejido representan la diversidad de elementos que pueden afectar al mismo. De esta manera, a continuación nos detendremos a discutir este esquema brevemente, enumerando y analizando cada elemento.

La parte central la ocupa el sujeto colectivo, que en el caso que nos ocupa se trata del ejido. Dentro de esta figura hemos ubicado las siguientes características a analizar:

1. Capital social. Dentro del capital social incluimos -siguiendo a Ostrom y Ahn (2003)- la confianza y las normas de reciprocidad; las redes de participación civil y las reglas o instituciones informales. En el caso que nos ocupa podríamos realizar un análisis de redes del ejido y una sistematización de las normas y sanciones constituidas para las asambleas y los diferentes grupos de trabajo internos.

2. Relaciones de parentesco. Las formas particulares de los vínculos de parentesco influencian en las relaciones de poder internas del ejido y también en los procesos de resolución de conflictos que puedan darse en un contexto de reforma agraria.

3. Relaciones de género. En este sentido, es de especial importancia las formas de participación social de hombres y mujeres en los órganos de decisión internos del ejido y los roles diferenciados asignados a cada uno.

4. Historia del ejido. Historia de la formación y estructura interna del ejido. En este caso, centrando nuestra atención especialmente a la transformación de sus instituciones locales y la existencia de conflictos internos previos, y a los 


\section{perifèria}

Número 16, junio 2012

\section{revistes.uab.cat/periferia - www.periferia.name}

procesos de resolución de conflictos mediante la toma de decisiones colectivas.

5. Migraciones. Revisar la existencia de movimientos migratorios dentro del propio ejido y especialmente la persistencia o no, de las redes colectivas en el proceso migratorio. Esta característica nos puede señalar, por ejemplo, si se tratan de migraciones por motivos económicos derivados de la escasez de recursos en el ejido, así como su posible vinculación con la venta de tierras. También hemos de tener en cuenta cómo han afectado los procesos migratorios externos e internos a los cambios en la densidad demográfica del ejido.

6. Sistema de creencias. Revisar la existencia de un sistema de creencias compartido y de qué manera este sistema simbólico de creencias está vinculado con la tenencia de propiedad social, y por lo tanto, la cosmovisión creada en torno a la relación comunidad-naturaleza. También es importante observar la posible presencia de templos religiosos en el ejido y de qué manera forman parte de la estructura del ejido.

7. Avencindados/posesionarios. Tal y como analizamos en los estudios de caso, el número de posesionarios y avecindados puede afectar a las dinámicas colectivas de toma de decisiones en las asambleas. Además de poder ejercer nuevos derechos dentro de las instituciones locales para la organización colectiva según la legislación de cada estado.

8. Instituciones locales de acción colectiva. Analizar qué instituciones locales conforman el ejido y qué reglamentos de funcionamiento tienen. Investigar cuál ha sido el proceso de gestación de estas instituciones y sus procesos de cambio.

9. Contexto socio-económico. Como hemos comentado anteriormente, el contexto socio-económico del ejido puede ser uno de los factores determinantes para participar en el programa PROCEDE y por lo tanto, en la decisión de parcelar o no sus tierras. De manera que es necesario analizar tanto el momento socio-económico actual del ejido, como el proceso 


\section{perifèria}

Número 16, junio 2012

\section{revistes.uab.cat/periferia - www.periferia.name}

histórico del mismo.

10. Condiciones biofísicas. Se han de tener en cuenta los propios condicionamientos del entorno y por lo tanto, el tipo de recursos naturales que se manejan desde el ejido. Además de otras circunstancias ambientales más específicas, como puede ser una sequía prolongada en el ejido. Ya que estas circunstancias pueden afectar en su toma de decisiones sobre la parcelación de sus tierras como vía para rentar o vender sus tierras y obtener ingresos fácilmente.

11. Prácticas de conservación. Analizar el tipo de prácticas de conservación llevadas a cabo desde el ejido. Además de analizar los discursos locales en torno al concepto de conservación y la historia local de estas prácticas.

12. Estrategias autónomas de supervivencia. Revisar cuáles son las estrategias locales para el mantenimiento de la estructura socioeconómica del ejido. Por ejemplo, que el ejido pueda mantener una agricultura de subsistencia y además otras formas de producción dirigidas, total o parcialmente, al mercado (como la producción de miel y la creación de cooperativas de productores), pueden ser estrategias de supervivencia del propio ejido dirigidas a mantener una diversidad productiva, además de respetuosa y sustentable con su medio ambiente.

13. Nivel de gobernanza. Siguiendo la definición de Prats (2003: 244), entendemos por gobernanza "un sistema institucional que enmarca la acción de los actores sociales y la acción de gobernar y que incluye la política, las políticas públicas y la administración pública". De esta manera, es importante analizar la existencia y el reconocimiento dentro del ejido de procesos de gobernabilidad a diferentes escalas (local, estatal, nacional e internacional).

En el recuadro izquierdo aparece el contexto socio-político a diferentes escalas: municipal, estatal, federal e internacional. Este recuadro pretende reflejar el contexto político multiescalar que puede afectar al ejido. Dentro de este recuadro 


\section{perifèria}

Número 16, junio 2012

\section{revistes.uab.cat/periferia - www.periferia.name}

creemos importante tener en cuenta los siguientes elementos:

1. Políticas de ayuda al campo. Es decir, los subsidios para los colectivos de productores y las capacitaciones ofertadas a los ejidatarios u otras personas interesadas del ejido y destinadas a la mejora en el manejo de sus recursos.

2. Figuras jurídicas de asociación y producción rural. Tener en cuenta las diferentes figuras jurídicas constituidas en el ejido, como pueden ser las cooperativas de productores o asociaciones civiles.

3. Participación y representación política local. Instrumentos públicos de participación destinados a la población local de los ejidos.

4. Instrumentos para el reconocimiento de la diversidad cultural. Como por ejemplo, el reconocimiento político de los "usos y costumbres" o de las lenguas indígenas utilizadas en el ejido.

En el recuadro derecho hemos representado a la diversidad de agentes externos que creemos que pueden influir en la toma de decisiones del propio ejido. Entre ellos creemos que son de especial importancia para la incidencia de la nueva reforma agraria en las instituciones locales de acción colectiva del ejido las siguientes:

1. Procuraduría Agraria. En el caso que nos ocupa, los agentes de la Procuraduría Agraria son los encargados de llevar acabo el programa PROCEDE. Y tal y como hemos observado en los estudios de caso pueden ejercer un papel importante en la toma de decisiones del ejido.

2. ONG's u otras entidades externas. Analizar la existencia de ONG's externas $\mathrm{u}$ otras organizaciones que intervengan en el ejido y que puedan ser relevantes para el proceso de toma de decisiones sobre las reformas agrarias y el programa PROCEDE.

3. Inversores agroindustriales. Analizar la existencia de inversores agroindustriales interesados en el ejido. Y que, ya sea por su ubicación, sus recursos naturales, u otro tipo de intereses, puedan influir en los procesos de decisión colectiva sobre la reforma agraria. 


\section{perifèria}

Número 16, junio 2012

\section{revistes.uab.cat/periferia - www.periferia.name}

Por todo ello, creemos que la incidencia de la nueva Ley Agraria y del art. 27 Constitucional en los ejidos puede variar según una diversidad de factores contextuales como los mencionados anteriormente. Esta diversidad también se traduce en una diversidad de "resultados" en las decisiones de los ejidos sobre la reforma agraria. Esta diversidad de resultados la representamos a continuación:

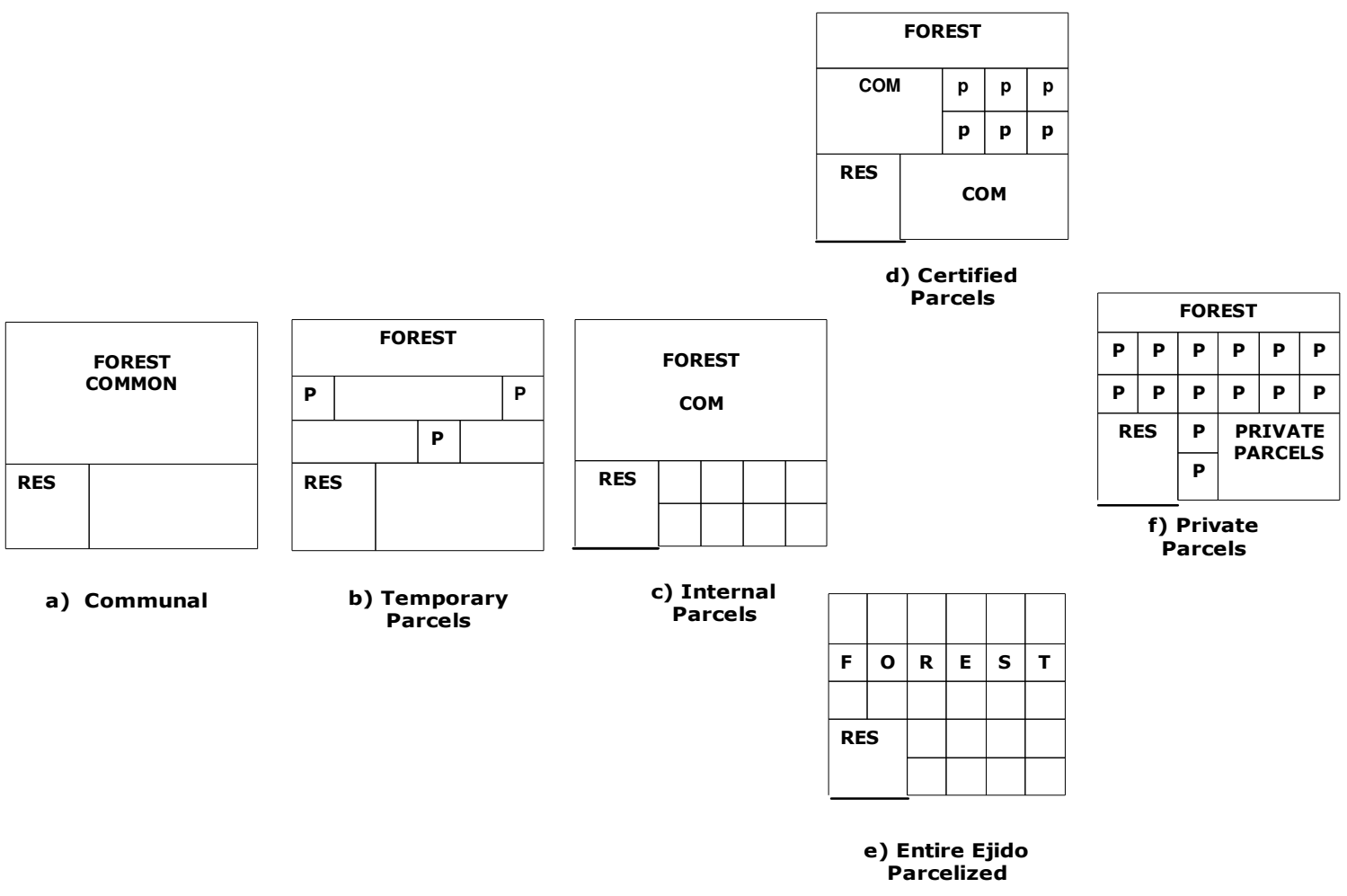

Figura 3. Cambios en la tenencia de la tierra (Barsimantov 2010:305)

(Res $=$ Residencias, Com $=$ Comunes, $\mathrm{P}=$ Parcelas $)$

a) Tenencia Colectiva. El ejido está compuesto por un asentamiento humano donde se encuentran todas las casas de los grupos domésticos que lo componen, y alrededor existen tierras de cultivo de gestión colectiva, siendo también los recursos forestales de propiedad colectiva.

b) Parcelas Temporales. Se trataría de un ejido similar al anterior, pero 


\section{perifèria}

Número 16, junio 2012

\section{revistes.uab.cat/periferia - www.periferia.name}

añadiendo la existencia de cesiones temporales de parcelas para el usufructo individualizado por parte de miembros del ejido, y bajo el permiso de la asamblea ejidal. Generalmente, este acuerdo de gestión temporal cesa cuando el ejidatario deja esta parcela en desuso o por otras cuestiones que la asamblea ejidal considere.

c) Parcelas Internas Indefinidas. Este sería el caso de los ejidos que deciden parcelar parte de sus tierras de uso común para la gestión indefinida por parte de ejidatarios del mismo ejido.

d) Parcelas Certificadas. En este caso el ejido ha entrado en el programa PROCEDE parcelando parte de sus tierras de uso común con la posibilidad añadida de su venta o renta a agentes externos del ejido. Esta es la opción más generalizada a la que han optado los ejidos que han decidido entrar en el programa PROCEDE.

e) Pequeños Propietarios Privados. En este caso no se trataría de un ejido, sino de la nueva configuración jurídica establecida desde la reforma agraria en la tenencia de la tierra. De esta manera, un grupo puede reclamar unas tierras pagando por ellas al estado, a cambio de su ubicación como pequeños ranchos en esa región. Esta es la opción que han tomado todos aquellos grupos que quisieran formarse como ejido después de la reforma agraria de 1992. Y en general de todos los colectivos que a partir de entonces quisieran demandar tierras.

f) Ejido Parcelado Entero. En este caso el ejido ha decidido a través de su entrada en el programa PROCEDE la parcelación entera de todas sus tierras y recursos forestales de propiedad colectiva.

Este modelo de análisis, para la aplicación en estudios de caso sobre los cambios en la tenencia de la tierra desde las reformas legislativas de 1992 en México, es una primera propuesta de recopilación de toda la información obtenida desde el proceso de investigación de la tesina presentada en Septiembre de 2011. Por lo tanto, está abierta a futuras modificaciones e implementaciones, y está formulada desde la intención de continuar investigando sobre cómo el PROCEDE ha afectado y está 


\section{perifèria}

Número 16, junio 2012

\section{revistes.uab.cat/periferia - www.periferia.name}

afectando a las gestiones comunitarias.

\section{Conclusiones}

El proceso de investigación que se está llevando acabo es una aproximación a un sujeto colectivo, el ejido, y concretamente a aquel que está inmerso en la gestión colectiva de comunes locales. Entendemos los comunes no exclusivamente como "bienes" comunes, es decir, como recursos, sino como la vinculación de los recursos con las personas que los gestionan. Por ello, desde esta investigación, hemos conceptualizado los comunes como una relación social de un sujeto colectivo con los recursos naturales que maneja.

Las reformas legislativas emprendidas desde 1992 en México no han producido una venta de tierras generalizada, tal y como algunas primeras conclusiones aparentemente precipitadas se aventuraron a enunciar inmediatamente después de las reformas (Morett 2003). Esta investigación no pretendía llegar a conclusiones deterministas, o a dicotomías reduccionistas sobre la afección de este proceso legislativo en las instituciones locales de los ejidos. Por ello, tampoco podemos enunciar que la propiedad privada sea sinónimo de sobreexplotación, igual que la propiedad colectiva no es sinónimo de conservación o "democracia". Obviamente no existen panaceas, pero no por ello vamos a invisibilizar que este proceso de reforma lejos de "democratizar el campo", ha promovido la inversión de grandes empresas agroindustriales al campo mexicano

El ejido continúa siendo la figura jurídica colectiva predominante en México, y a pesar de algunos análisis casi apocalípticos enunciados tras las reformas, consideramos que difícilmente desaparecerá. Pero no por ello, hemos de obviar que la nueva reforma agraria ha finalizado con el ejido a través de la dotación de tierras, de manera que desde 1992, la figura del ejido ha sido deslegitimada como figura jurídica colectiva en México. Desde entonces, la única opción para constituirse como ejido es a través de la unión de un mínimo de veinte personas que, constituidas previamente como pequeños propietarios, decidan realizar la compra de terrenos de forma colectiva. Opción que casi veinte años después de la 


\section{perifèria}

Número 16, junio 2012

\section{revistes.uab.cat/periferia - www.periferia.name}

reforma, prácticamente no se ha llevado a cabo en México (Barsimantov et al. 2010).

Consideramos tal y como enuncia Morett:

El ejido, por más problemas que tenga, presenta un importante aspecto que debe ser tomado en cuenta: la experiencia de organización de sus miembros (...). La organización, aunque con una serie de deficiencias, es el elemento central a rescatar de la experiencia de la vida ejidal. (Morett 2003: 204)

Por todo ello, y evitando crear nuevas panaceas, creemos que es importante visibilizar y reconocer, por una parte, la capacidad organizativa del ejido, y por otra parte, los conocimientos ecológicos locales que se dan en la gestión colectiva de los recursos naturales, tanto por la diversidad biológica que albergan, como la diversidad cultural que representan.

\section{Bibliografía}

Achenson J.M. (1991). La administración de los recursos de propiedad colectiva. En: Consejo Nacional para la Cultura y las Artes y Alianza Editorial (1991) Antropología económica. México, Alianza, 476-512.

Agrawal A. (2001). "Common Property Institutions and Sustainable Governance of Resource". World Development, 29:10, 1649-1672.

Barsimantov J et al. (2010). "Tenure, tourism and timber in Quintana Roo, Mexico: Land tenure changes in forest ejidos after agrarian reforms". International Journal of the Commons, no 4, 293-318.

Berkes F. (1999). Sacred ecology: traditional ecological knowledge and management systems. UK, Taylor \& Francis, Philadelphia and London.

(2002). "Cross-scale institutional linkages: perspectives from the bottom up". En: Ostrom E, Dietz T, Dolsak N, .Stern P.C, Stonich S, and Weber E., eds. The 


\section{perifèria}

Número 16, junio 2012

\section{revistes.uab.cat/periferia - www.periferia.name}

drama of the commons. Washington, D.C. National Academy Press, 293-321.

Boege E. (2004). Acerca de la diversidad bio-cultural y los recursos biológicos colectivos de los pueblos indígenas de México. Proyecto presentado en el taller de "Conservación de Sitios Sagrados Ricos en Biodiversidad", México.

Braña J, Martínez A. (2005). "El PROCEDE y su impacto en la toma de decisiones sobre los recursos de uso común". Gaceta Ecológica no 74, 35- 49.

Bray, D, Merino L. (2004) La experiencia de las comunidades forestales en México. México, Semarnat, INE y CCMSS.

Chamoux M, Contreras J. eds. (1996) La gestión comunal de los recursos. Economía y poder en las sociedades locales de España y América Latina. Barcelona, Icaria.

Concheiro L. et al. (2001) Una perspectiva campesina del mercado de tierras ejidales. Siete estudios de caso. México, Universidad Autónoma de México.

De Ita A. (2003) México: Impactos del Procede en los conflictos agrarios y la concentración de la tierra. [En línea] página web. Centro de Estudios para el Cambio en el Campo Mexicano, SECAM.

http://www.landaction.org/gallery/Mon\%20PaperMEXICOSpan.pdf [Consulta, 02.02.2012 ].

Dietz G. (2005). "Del indigenismo al zapatismo: la lucha por una sociedad mexicana multi-étnica". En: Grey N, Zamosc L., eds. (2005) La lucha por los derechos indígenas en América Latina. Quito, Aya-Yala, 53-128.

Falconí F, Hercowitz M, Muradian R. (2004) Globalización y desarrollo en América Latina. FLACSO- Ecuador, Red Iberoamericana de Economía Ecológica.

Hardin G. (1968). Tragedy of the Commons. Science, 162, 1243-1248.

Hernández R. A. (2001) La otra frontera:Identidades múltiples en el Chiapas poscolonial. México, Miguel Ángel Porrúa.

Léonard E, Velázquez E. (2007). "La producción local de la regulación agraria: del 


\section{perifèria}

Número 16, junio 2012

\section{revistes.uab.cat/periferia - www.periferia.name}

reparto agrario al PROCEDE. Autonomía local y resignificación del cambio legal en una micro-región indígena del Istmo veracruzano". Ulúa. Revista de Historia, Sociedad y Cultura, no. 9, 155- 194.

Léonard E. (2003). "Titularización agraria y apropiación de nuevos espacios económicos por los actores rurales: el Procede en los Tuxtlas, Estado de Veracruz". En: Léonard E. Quesnel A, Velázquez E. coords. (2003) Políticas y regulaciones agrarias. Dinámicas de poder y juegos de actores en torno a la tenencia de la tierra. México, CIESAS.

Mackinlay H. (1991). "La política de reparto agrario y las reformas al artículo 27 Constitucional". En: Massolo et al. (1991) Procesos rurales y urbanos en el México actual. México, UAM Iztaplapa.

Maffi L. (2001). On biocultural diversity: linking language, knowledge, and the environment. Washington, D.C., Smithsonian Institution Press.

Maldonado, S. (2010). "Nuevas ciudadanías en el México rural. Derechos agrarios, espacio público y el Estado neoliberal". Liminar. Estudios Sociales y Humanísticos, vol. VIII, no 1 , Junio, 46-63.

Martin et. al. (2010). "Negotiating the Web of Law and Policy: Community Designation of Indigenous and Community Conserved Areas in México". Policy Matters no 17.

Mattiace S, Hernández L, Rus J. (2002). Tierra, libertad y autonomía: Impactos regionales del zapatismo en Chiapas. México, CIESAS.

Mercado A, Cohen M. (2010). "Región y dinámica ambiental". En: Mercado A., coord. (2010). Reflexiones sobre el espacio en las ciencias sociales: enfoques problemas y líneas de investigación. México, Universidad Autónoma Metropolitana. Unidad Cuajimalpa. Juan Pablos Editor, S.A, 77-104.

Merino L. (2004). Conservación o deterioro. El impacto de las políticas públicas en las instituciones comunitarias y en las prácticas de uso de los bosques en México. México, Instituto Nacional de Ecología.

(2006). "Apropiación, instituciones y gestión sostenible de la biodiversidad". 


\section{perifèria}

Número 16, junio 2012

\section{revistes.uab.cat/periferia - www.periferia.name}

Gaceta Ecológica, Instituto Nacional de Ecología, nº.78, 11-28.

Morett J. (2003). Reforma agraria: del latifundio al neoliberalismo. México, Plaza y Valdés.

Nietschmann B. (1992). "The interdependence of biological and cultural diversity". Occasional Paper n021. Olympia, WA., Centre of World Indigenous Studies.

Ostrom E. (2000 [1990]). El Gobierno de los bienes Comunes. La evolución de las instituciones de acción colectiva. México, Fondo de Cultura Económica.

(2005). Understanding Intitutional Diversity. Princeton, University Press.

Ostrom E, Ahn T.K.(2003). "Una perspectiva del capital social desde las ciencias sociales: capital social y acción colectiva". Revista Mexicana de Sociología. Vol. 65. No 1. Ene/ Mar.

Ostrom E, Hess C. (2007). Private and Common Property Rights. Social Science. [En línea] página web http://ssrn.com/abstract=1304699 [Consulta, 07.03.2012].

Pascual J. (1996). "El paradigma de la tragedia de los comunes y el caso de los pescadores". En: Chamoux y Contreras, eds. (1996) La gestión comunal de recursos. Economía y poder en las sociedades locales de España y América Latina. Barcelona, Icaria.

Pretty J, Smith, D. (2004). "Social capital in biodiversity conservation and management". Conservation Biology n¹8, 631-638.

Rentería C. (2010). De la Ley Lerdo a la Reforma Agraria en México. Desamortización y restitución de los ejidos en el municipio de la Antigua (Veracruz). España, IESA-CSIC.

(2011). "Cambio y continuidad en los derechos de propiedad sobre las tierras ejidales en México". Instituto de Estudios Sociales Avanzados (IESA). [En línea] página web http://hdl.handle.net/10261/34681 [Consulta, 23.07.2011].

Rivera, G. (2007). La reforma agraria de 1992: impactos en ejidos y comunidades del Estado de México. México, Universidad Autónoma del Estado de México. 


\section{perifèria}

Número 16, junio 2012

\section{revistes.uab.cat/periferia - www.periferia.name}

Robles H. (2008). "Saldos de las reformas de 1992 al Artículo 27 Constitucional". Estudios Agrarios no 38, 131-150.

Ruiz M. (1994). "Régimen Agrario y Reformas al artículo 27 Constitucional". En Melgar M, Soberanes J.L, Massieu, M. (1994) La Rebelión en Chiapas y el Derecho. México, Universidad Autónoma Nacional de México. Instituto de Investigaciones Jurídicas.

Scott, J. (2004). Los dominados y el arte de la resistencia. México, Era.

Sousa Santos B. (2005). "Hacia una sociología de las ausencias y una sociología de las emergencias". En: Sousa Santos B. (2005) El milenio huérfano: ensayos para una nueva cultura política. España, Trotta, 151- 192.

Téllez L. (1994). La modernización del sector agropecuario y forestal. México, Fondo de Cultura Económica.

Toledo V, Barrera-Bassols N. (2008). La Memoria Biocultural: la importancia ecológica de las sabidurías tradicionales. Barcelona, Icaria Editorial.

Vargas M.A, Ochoa F y Gustavo D. (2008). "Tenencia de la tierra y conservación de tierras privada". En: Gustavo D, Exequiel E., eds. (2008) Bahía de los Ángeles: Recursos Naturales y Comunidad. Línea Base 2007. México, Pronatura Noroeste, A. C. / Secretaria de Medio Ambiente y Recursos Naturales / Instituto Nacional de Ecología / San Diego History Museum.

Varo R. (2002). La reforma agraria en México desde 1853. Sus tres ciclos legales. México, Universidad de Guadalajara/UCLA-Program on Mexico/Juan Pablos Editor.

Zendejas S, Vries P. (1998). Las Disputas por el México Rural: Transformaciones de Prácticas, Identidades y Proyectos. México, Colegio de Michoacán. 